\title{
Monitoring and Evaluation Work Plan on Provision of Curative and Preventive Tuberculosis Healthcare Services in Institutions of Public Health in Kisumu County, Kenya
}

\author{
John Odhiambo Oluoch, Charles M Rambo, and Pokhariyal Ganesh
}

\begin{abstract}
This research was focused on assessing how monitoring and evaluation work plan influence provision of curative and preventive tuberculosis healthcare practices in institutions of public health in Kisumu County, Kenya. The study unit of analysis was public health institutions that practice M\&E system on provision of health care services. The target population consisting of doctors, $M \& E$ officers, clinical officers, nurses and patients in four public health institutions in Kisumu county, Kenya. The study was guided by pragmatism paradigm. A descriptive survey research design was employed to collect both quantitative and qualitative data and correlational design was used to test the hypothesis. A sample of 221 respondents was selected from a population of 517 using stratified random sampling. A structured questionnaire with both open and close ended with Likert type on 1-5 five point scale and interview schedule was used to collect data. A descriptive survey research design was employed to collect both quantitative and qualitative data and correlational design was used to test the hypothesis. Quantitative data was analyzed using descriptive and inferential statistics and data presented in frequency tables using means and standard deviations while qualitative data was presented in in narrative statements. Hypothesis was tested using linear regression at 0.05 level of significance to determine the degree and direction of relationships among variables. The study attained reliability of instruments using Cronbach Alpha coefficient of 0.735 for all items implying that the instrument was reliable. The results indicated that showed that $M \& E$ work plan regression was $\left(r_{2}=0.028, p<0.05\right)$. The study results indicated that present results for quantitative data based on composite mean score of 3.90 and 0.447 standard deviation for this variable. M\&E system therefore, contributes significantly to the effective provision of curative and preventive tuberculosis health care services in public health institutions.
\end{abstract}

Index Terms - Monitoring and Evaluation System; M\&E Work Plan; Stakeholder Participation; Organizational Structure and Provision of Curative and Preventive Tuberculosis Health Care Services

\section{INTRODUCTION}

Health care services provision is paramount and regarded as a fundamental right of an individual globally as acknowledged in the millennium development goals United [12]. Due to the complexities and the nature of healthcare services, it's the government's main 1responsibility to ensure that public health institutions deliver adequate health care services [1]. However, the broader health care service delivery has been faced with challenges affecting public health institutions and hence not made it impossible to achieve the intended objectives. The global tuberculosis annual report main is to provide a comprehensive and up to date assessment of TB epidemic and progress in prevention, diagnosis and treatment of the disease, at global, regional and country levels [13]. The report indicated the countries that are highly burdened with Africa mostly affected. China, India, Indonesia, Philippines and Pakistan are among other countries with the highest infection. In Kenya, the report shows that the rate of drug-resistance TB care, 2018 of bacteriologically confirmed new cases were $64 \%$ and the previous cases treated were $79 \%$.

The objectives by millennium development goals suggest that everyone with TB should have access to the innovative tools and services they need for rapid diagnosis, treatment and care and intensified global solidarity and action to ensure the success of transformative end of TB strategy. The world health organization outlined pillars that would bring together critical interventions to ensure that all people with TB have equitable access to high quality diagnosis, treatment care and prevention, without facing catastrophic expenditure [13]. The integrated patient-centered TB care prevention that focuses on early detection, treatment and prevention for all TB patients including children not only to have equal, unhindered access to affordable services. Bold policies and supportive systems that requires intense participation across government, communities and private stakeholders and to intensified research and innovation that research is critical to break the trajectory of the epidemic and reach the global targets.

The [13] global priority indicators and targets for monitoring the implementation that would end TB strategy based on treatment coverage, TB treatment success rate, and preventive treatment coverage, uptake of new diagnostics and new drugs of about $90 \%$ and above with $0 \%$ TB affected household facing catastrophic costs. M\&E work plan of health care activities are outlined against resources allocation, implementation against provision of curative and preventive tuberculosis healthcare services to achieve the intended outcome. This will demonstrate its significance that will ensure work efficiency, transparency and accountability in expenditures therefore, all the activities that are undertaken be subjected to the work plan.

G. P. is with the Mathematics Department, University of Nairobi, Kenya [gppokhariyal@gmail.com] 


\section{A. Statement Of The Problem}

Monitoring and evaluation work plan is significant in the ensuring that the programs of health care activities are effectively implemented in delivery of curative and preventive tuberculosis health care services. However, lack or inappropriate $M \& E$ work plan attributes to inadequate and inefficient implementation of the desired health care programs that are intended to improve on provision of curative and preventive tuberculosis health care services.

\section{B. Objective Of The Study}

The study objective was to assess how monitoring and evaluation work plan influence on provision of curative and preventive tuberculosis healthcare practices in institutions of public health in Kisumu County, Kenya

\section{Hypothesis Of The study}

Ho Monitoring and evaluation work plan has no significant influence the provision of curative and preventive tuberculosis healthcare services in institutions of public health in Kisumu County.

\section{LITERATURE REVIEW}

In the 20th century, the world health organization WHO [2008] championed for the provision of health care in each country that is provided by the public health institutions funded by the government. Health care has been defined differently but the study therefore, referred health care as the prevention, treatment and managing of illness and preserving mental and physical wellness in offered medical services in alignment to health care professionals [7]. Good health care delivery is significant for the health care system that will ensure effective provision of health care services to the public. Previous studies indicated that the populace does not have much trust in the services offered by the public health institutions since they don't guarantee the expected results to the beneficiaries [5]. The [15] assertion that the globalization has an influence on the world health systems and that the other health providers are not in a position to manage the health system and this therefore, leads to the search and mobilization and funding that can be consolidated to manage the health systems Researchers acknowledged that it is appropriate that heath care can hugely impact the country's health care systems that can be relied upon health care service provision [9].

Geographically, health care services have different barriers that hinders access for the less fortunate people especially in remote areas where there is neither near health service provider nor lack of health care institution [4]. The TB Bacillus Calmette-Guerin [BCG] vaccine is the most preferred approximated with about $80 \%$ of new born babies and infants in the national immunization programme suggested by the [14]. Despite of the massive use of the vaccine, the BCG vaccine has been proved to be effective in the prevention of the widespread of all forms of TB. The pulmonary TB is varied in adults and various TB vaccines are at disposal to control the disease with the BCG vaccine usually used to prevent $\mathrm{TB}$ in children. The treatment of the disease is focused on the adherence to the treatment schedule that involves the follow up to ensure that the patients complied with the treatment to its completion. The U.S. Food and Drug Administration [FDA] in the recent past has approved ten different types of vaccines that can be used to treat tuberculosis with the TB anti-vaccines forming the center of curing vaccines the treatment duration depending on the by times of doses ingested over a specific duration of time [6].

Monitoring and evaluation work plan defined as a fundamental document with detailed description which is integrated with strategic information obtained from the various data collection systems that are used to make decisions that improves programs [10]. It ensures accountability and implementation that is focused towards effective provision of curative and preventive tuberculosis health care services to patients. Nonetheless, it enhances flexibility for the adjustments that fits in the proposed health care activities that benefit the beneficiaries. A survey conducted by [8] conducted a study on systematic approach to planning, implementation, monitoring and evaluation of integrated health services in United States. Systematic research design and interventions was applied. The sample was drawn using systematic approach to help in planning of the programs. The study used logic models as instrument of data collection which requires the general description that provide credibility relating to a sequence of that defines the contributions, part played and accountability, pointer and the origin of data toward the health system.

Data was analyzed using the fundamental assumption of the understanding reality in monitoring and evaluation framework. The study found that, health system improvement and data application ensured informed decision making. This is due to alternatives in M\&E function enable it to be more formidable as well as to ensure effective service delivery, action and administrative competence. The study adopted six step systematic approaches of M\&E entirely instead of detailed qualitative and quantitative design which has the ability to gather in-depth information significant for realistic decision making in similarity with this study in which the study outlined data collection method and research design. Strong M\&E system can provide the information management require in decision making and to present facts that impact health outcome [11].

\section{A. Theoretical Framework}

The study adopted planning theory with the view that planning is significance in the implementation of health activities are in accordance to the scheduled plan. This theory was developed [2], [3], provided a basic principle for planners to consider since planning is a norm of practice that practitioners cannot do without in delivering the services that delivers results. The assured way is to plan based on the intended outcome, how to go about it through the formal process that is accounted to ensure the delivered results is achieved according to the plan.

\section{B. Conceptual Framework}


The study focused on assessing how monitoring and evaluation work plan influence provision of curative and preventive tuberculosis healthcare practices in institutions of public health in Kisumu County, Kenya. The four key indicators of $\mathrm{M} \& \mathrm{E}$ work plan were used include the following, finances for facilitation and implementation, time frame to achieve the results, program sequences as planned, plan reviewed and work schedule. The relationship among the study variables are presented in figure 1 .

\section{Dependent}

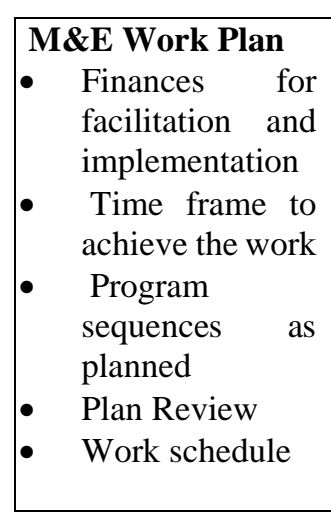

\section{Independent}

\begin{tabular}{|l|}
\hline Provision of \\
Curative and \\
Preventive \\
Tuberculosis Health \\
Care Services in \\
Public Health \\
Institutions \\
- $\quad$ Accessibility \\
- $\quad$ Diagnosis \\
- $\quad$ Treatment \\
- $\quad$ Cuality \\
- $\quad$ Person \\
- $\quad$ Vacenteredness \\
\hline
\end{tabular}

Fig. 1: Conceptual framework for M\&E work plan influence on provision of curative and preventive tuberculosis healthcare practices in institutions of public health in Kisumu County, Kenya

\section{RESEARCH METHODOLOGY}

The study was guided by pragmatism paradigm where descriptive survey and correlational research design was used. The design chosen were appropriate as they enabled collecting both quantitative and qualitative data at the same time testing hypothesis. The target population was 517 where an independent sample of 221 was drawn using proportionate method. Structured questionnaires and interview schedule were used to collect the data. The study used Cronbach Alpha of coefficient of 0.735 for all items implying that the instrument was reliable. For analysis of quantitative data, inferential and descriptive statistics were used simultaneously while tables showing means and standard deviations used to present results. Presentation of qualitative data was done in narrative form. Hypothesis was tested using linear regression at 0.05 level of significance.

\section{FINDINGS AND DISCUSSION}

A sample size drawn from the target population was 221 who were issued with questionnaires out of which 187 questionnaires were duly filled correctly and returned for data analysis. The results are presented in Table1.
TABLE I: QUESTIONNAIRES RETURN RATE

\begin{tabular}{lcc}
\hline Responses & Frequency & Percentage \\
\hline Responses & 187 & 84.6 \\
Non-responses & 34 & 15.4 \\
\hline Total & $\mathbf{2 2 1}$ & $\mathbf{1 0 0}$ \\
\hline
\end{tabular}

\section{A. General Information about Respondents}

The areas covered under this section include; gender, highest level of education, age of the respondents and category of respondents are presented table II.

TABLE II: RESPONDENTS GENDER

\begin{tabular}{lccc}
\hline Gender & $\boldsymbol{\%}$ & Frequency & CF \\
\hline Male & 42.2 & 79 & 42.2 \\
Female & 57.8 & 108 & 100 \\
\hline Total & $\mathbf{1 0 0}$ & $\mathbf{1 8 7}$ & \\
\hline
\end{tabular}

The study results on gender indicated that 108 [57.8\%] of the respondents were male while $79 \%$ [42.2\%] of the respondents were female. These findings show that the number of females were higher than male. This implies that issue of gender equality still a challenge. However, the $1 / 3$ rule is at least adhered to.

TABLE III: BASED ON LEVEL OF EDUCATION

\begin{tabular}{lclc}
\hline \multicolumn{1}{c}{ Level } & frequency & \% & CF \\
\hline Certificate & 33 & 17.6 & 17.6 \\
Diploma & 53 & 28.3 & 46.0 \\
Degree & 72 & 38.5 & 84.5 \\
Masters & 26 & 13.9 & 98.4 \\
PhD & 3 & 1.6 & 100.0 \\
\hline Total & $\mathbf{1 8 7}$ & $\mathbf{1 0 0 . 0}$ & \\
\hline
\end{tabular}

On issues of highest level of education, out of 187 respondents who participated in the study, 3 [1.6\%] of the respondents had $\mathrm{PhD}$ degree, 26 [13.9\%] had Master's degree, 72 [38.5\%] had Bachelor's degree, 53 [28.3\%] had Diploma and 33 [17.6\%] had Certificate level of education. These findings showed that the number of respondents reduces as the level of education increases and hence adequately qualified. This implies that there were adequate academic qualifications that qualify the respondents suitable in their line of duties respectively that contribute to effective provision of curative and preventive tuberculosis health care services to the public.

\begin{tabular}{lccc}
\multicolumn{4}{c}{ TABLE IV: BASED ON AGE OF RESPONDENTS } \\
\hline Age & frequency & $\%$ & CF \\
\hline Below 25 years & 20 & 10.7 & 10.7 \\
25 - 30 years & 43 & 23.0 & 33.7 \\
31 - 35 years & 35 & 18.7 & 52.4 \\
36 - 40 years & 45 & 24.1 & 76.5 \\
41 - 45 years & 17 & 9.1 & 85.6 \\
46 - 50 years & 16 & 8.6 & 94.1
\end{tabular}




\begin{tabular}{lcrr} 
Above 50 years & 11 & 5.9 & 100.0 \\
\hline Total & $\mathbf{1 8 7}$ & $\mathbf{1 0 0}$ &
\end{tabular}

The age bracket of the respondents below 25 years were 20 [10.7\%], between 26 - 30 years 43 [23\%], between 31-35 years were 35 [18.7\%], between 36 - 40 years were 45 [24.1\%], between $41-45$ years were 17 [9.1\%], $46-50$ years were 16 [8.6] and above 51 years were 11 [5.9] \%. These finding indicate that the public health institution attracted the respondents of diverse age categories hence, cordial interaction leading to mutual understanding improving on provision of curative and preventive tuberculosis health care services.

\begin{tabular}{|c|c|c|c|}
\hline Category & frequency & $\%$ & $\mathbf{C F}$ \\
\hline Medical Doctors & 32 & 17.1 & 17.1 \\
\hline M \& E Officers & 13 & 7.0 & 24.1 \\
\hline Clinical Officers & 17 & 9.1 & 33.2 \\
\hline Nurses & 21 & 11.2 & 44.4 \\
\hline Patients & 104 & 55.6 & 100.0 \\
\hline Total & 187 & 100.0 & \\
\hline
\end{tabular}

The study results showed that, 32 [17.1\%] of the respondents were Medical Doctors, 13 [7.0\%] were M\&E officers, 17 [9.1\%] were Clinical officers, 21 [11.2\%] were Nurses and 104 [55.6\%] were patients. These findings indicate that the respondents in the job category were normally distributed with the highest number of patient respondents seeking the health care services higher as expected. This means that the number of patients under this study seeking the curative and preventive tuberculosis health care services were many compared to the public health officers offering the health care services.

\section{A. Provision of Curative and Preventive Tuberculosis} Health Care Services in Public Health Institutions

The study indicators measured were, accessibility, diagnosis, treatment quality, continuity, person centeredness and vaccination of health care services. The results are presented in table 6 .

\section{TABLE VI: PROVISION OF CURATIVE AND PREVENTIVE TUBERCULOSIS ACCESSIBILITY OF HEALTH CARE SERVICES}

\begin{tabular}{lcc}
\hline Statements & Mean & SDV \\
\hline $\begin{array}{l}\text { The TB health care services offered } \\
\text { by the institution are directly accessible } \\
\text { without a barrier of cost }\end{array}$ & 4.22 & 0.415 \\
& &
\end{tabular}

TB patients face economic constraints

for the health care services to access

the treatment

The referred TB patients has direct access to TB healthcare services

The public awareness on how to access $\quad 3.80$ at the public heath institution

The TB patients are assured to access 4.23 0.592 to the drugs during and after the initial treatment

Composite mean and Std. Deviation 3.66 $\quad 0.631$

The study results show that $[\mathrm{M}=4.22, \mathrm{SDV}=0.415]$ majority of the respondents agreed that the TB health care services offered are directly accessible without a barrier of cost. The respondents also $[\mathrm{M}=3.36, \mathrm{SDV}=1.339]$ agreed that the TB patients face economic constraints for the health care services to access the treatment. Majority of the respondents $[\mathrm{M}=2.70, \mathrm{SDV}=1.424]$ disagreed that any referred TB patients has direct access to TB health care services. The majority of the respondents $[\mathrm{M}=3.80$, SDV $=1.141]$ agreed that the public awareness on how to access TB health care services at the public health institution. Majority of the respondents agreed $[\mathrm{M}=4.23, \mathrm{SDV}=0.592]$ that TB patients are assured to access the drugs during and after the initial treatment. The study results show that the aspect of accessibility influences provision of curative and preventive tuberculosis healthcare practices in institutions of public health.

\section{TABLE VII: PROVISION OF CURATIVE AND PREVENTIVE TUBERCULOSIS DIAGNOSIS OF HEALTH CARE SERVICES}

\begin{tabular}{lll}
\hline Statements & Mean & SDV \\
$\begin{array}{l}\text { The TB delay and untimely } \\
\text { diagnosis contribute to ineffective } \\
\text { treatment for the patients }\end{array}$ & 2.64 & 1.45 \\
& &
\end{tabular}

The TB patients seeking health care services must be diagnosed

before treatment

The institution encourages

$4.43 \quad 0.528$

mandatory diagnosis for

the referred patients before treatment

Diagnosed TB patients on $4.31 \quad 0.486$ treatment is enlightened on the measures to observe during the treatment

Upon the diagnosis, the patients are immediately put under treatment and surveillance

\begin{tabular}{lll}
\hline Composite mean and Std. Dev. & 3.96 & 0.374 \\
\hline
\end{tabular}

The study results show that the majority of the respondents $[\mathrm{M}=2.64, \mathrm{SDV}=1.450]$ disagreed that the tuberculosis delay and untimely diagnosis contribute to ineffective treatment of the patients does not influence provision of curative and preventive tuberculosis health care services. Therefore, the public health care providers should 
devise ways in which the disease could be diagnosed earlier and timely that leads to curb the diseases in its early stages to avoid further infections. Majority of the respondents [M= 4.23, SDV=0.793] agreed that the TB patients seeking health care services must be diagnosed before treatment. The respondents also $[\mathrm{M}=4.43, \mathrm{SDV}=0.528]$ agreed that the institution encourages mandatory diagnosis for the referred patients before treatment. Diagnosed TB patients on treatment are enlightened on the measures to observe during treatment. The majority of the respondents $[M=4.31$, $\mathrm{SDV}=0.486$ ] also agreed that the diagnosed TB patients on treatment are enlightened on the measures to observe during treatment. The study results showed that most of the respondents $[\mathrm{M}=4.21, \mathrm{SDV}=0.445]$ agreed that upon the diagnosis, the patients are immediately put under treatment and surveillance. On the aspect of diagnosis, it was noticed that it influences provision of curative and preventive tuberculosis health care services.

\section{TABLE VIII: PROVISION OF CURATIVE AND PREVENTIVE TUBERCULOSIS TREATMENTOF HEALTH CARE SERVICES}

\begin{tabular}{lll}
\hline Statements & Mean & SDV \\
\hline $\begin{array}{l}\text { Tuberculosis treatment is effectively } \\
\text { offered in the institution that meets }\end{array}$ & 4.36 & 0.504 \\
the patient's needs & &
\end{tabular}

The majority of TB patients delay to
seek treatment due to limited
knowledge of the disease

The suspected TB patients are $3.95 \quad 1.046$ subjected to immediate treatment to avoid the spread of the disease

There are positive results recorde in the treatment of the disease

TB treatment is advised to any suspected individual as an effort towards wipe out the disease

Composite mean and Std. Dev. $\quad 4.05 \quad 0.459$

The study results indicated that majority of the respondents $[\mathrm{M}=4.36, \mathrm{SDV}=0.504]$ agreed that the tuberculosis treatment is effectively offered in the institution that meet the patient's needs. Most of the respondents $[\mathrm{M}=$ $3.44, \mathrm{SDV}=1.324$ ] agreed that the majority of TB patients delay to seek treatment due to limited knowledge of the disease. The respondents also $[\mathrm{M}=3.95, \mathrm{SDV}=1.046]$ agreed that the suspected tuberculosis patients are subjected to immediate treatment to avoid the spread of the disease was in place.Most of the respondents $[\mathrm{M}=4.24, \mathrm{SDV}=0.662]$ acknowledged that there was positive results recorded in the treatment of the disease.Results indicated that the majority of the respondents $[\mathrm{M}=4.28, \mathrm{SDV}=1.141]$ agreed that tuberculosis treatment is advised to any suspected individual as an effort towards wipe out the disease.The results imply that treatment influence provision of curative and preventive tuberculosis health care services.

\section{TABLE IX: PROVISION OF CURATIVE AND PREVENTIVE TUBERCULOSISQUALITY OF HEALTH CARE SER VICES}

\begin{tabular}{lcc}
\hline Statements & Mean & SDV \\
$\begin{array}{l}\text { The curative and preventive } \\
\text { tuberculosis healthcare services }\end{array}$ & 4.14 & 0.562 \\
quality satisfy the patients & & \\
$\begin{array}{l}\text { The TB infection is due to lack of } \\
\text { proper health care service towards }\end{array}$ & 2.59 & 1.298 \\
the disease & & \\
$\begin{array}{l}\text { In adequacy for curative health } \\
\text { care services offered makes the }\end{array}$ & 2.22 & 1.173 \\
$\begin{array}{l}\text { TB persistent } \\
\text { The TB health care services vary } \\
\text { from one institution to another } \\
\text { hence influences the patient's } \\
\text { choice to seek services }\end{array}$ & \\
\hline Composite mean and Std. Dev. & $\mathbf{3 . 1 1}$ & $\mathbf{0 . 6 5 0}$ \\
\hline
\end{tabular}

The results of the study show that the majority of the respondents $[\mathrm{M}=4.14, \mathrm{SDV}=0.562]$ concurred that the curative and preventive tuberculosis health care services qualities satisfy the patients. The majority of the respondents $[M=2.59, \mathrm{SDV}=1.298]$ disagreed that the $\mathrm{TB}$ infection is due to lack of proper health care service towards the disease. This imply that there is need for the sensitization of the tuberculosis disease so that the public could be able to immediately report the infection to the health facilities to be treated and to curb the diseases in its early stages to avoid further infections. The majority of the respondents also [M= 2.22, SDV=1.173] disagreed that in adequacy for curative health care services offered make the tuberculosis persistent. Therefore, the public health institutions are in a position to provide curative and preventive tuberculosis health care services that meet the needs of the clients. Most of the respondents $[\mathrm{M}=3.48, \mathrm{SDV}=1.202]$ acknowledged that $\mathrm{TB}$ health care services vary from one institution to another hence influences the patient's choice to seek services.

\section{TABLE X: PROVISION OF CURATIVE AND PREVENTIVE TUBERCULOSIS \\ CONTINUITY OF HEALTH CARE SERVICES}

\begin{tabular}{lll}
\hline Statements & Mean & SDV \\
\hline The institution offers after & 4.13 & 0.425
\end{tabular}

treatment care to check on the

progress of the patients

The TB patients are put under

$4.20 \quad 0.506$

Surveillance while on drugs to ensure compliance 
There are positive results of TB $\quad 4.33 \quad 0.516$ patient's recovery under observation

\begin{tabular}{lll}
\hline Composite mean and Std. Dev. & 4.22 & 0.328 \\
\hline
\end{tabular}

The study results show that most of the respondents $[\mathrm{M}=$ 413, SDV=0.425] agreed that the institution offers after treatment care to check on the progress of the patients. Majority of the respondents $[\mathrm{M}=4.20, \mathrm{SDV}=0.506]$ disagreed that the tuberculosis patients are put under surveillance while on drugs to ensure compliance. Most of the respondents $[\mathrm{M}=4.33, \mathrm{SDV}=0.516]$ agreed that there are positive results of TB patient's recovery under observation meaning thatit influences provision of curative and preventive tuberculosis health care services.

\section{TABLE XI: PROVISION OF CURATIVE AND PREVENTIVE TUBERCULOSIS PERSON CENTEREDNESS OF HEALTH CARE SERVICES}

\begin{tabular}{lcc}
\hline Statements & Mean & SDV \\
\hline The health care services offered & 4.32 & 0.541
\end{tabular}

to users are perceived to be

responsive and acceptable to them

on disease treatment

$4.25 \quad 0.683$

rather than the patient

The TB patients are hopeful to get well once on treatment

Health care services provided $4.12 \quad 0.665$ guarantees positive responsiveness that hastens quick recovery

\begin{tabular}{lll}
\hline Composite mean and Std. Dev. & 4.26 & 0.385 \\
\hline
\end{tabular}

The study results indicated that the majority of the respondents $[\mathrm{M}=4.32, \mathrm{SDV}=0.541]$ agreed that the health care services offered to users are perceived to be responsive and acceptable to them. Majority of the respondents [M= $4.25, \mathrm{SDV}=0.683$ ] acknowledged that the treatment for TB is focused on the disease rather than the patient. Most of the respondents agreed $[\mathrm{M}=4.34, \mathrm{SDV}=0.631]$ that the $\mathrm{TB}$ patients are hopeful to get well once on treatment. The respondents also $[\mathrm{M}=4.12, \mathrm{SDV}=0.665]$ agreed that the health care services provided guarantees positive responsiveness that hastens quick recovery. The statement mean score imply that person centeredness influence provision of curative and preventive tuberculosis health care services.

\section{TABLE XII: PROVISION OF CURATIVE AND PREVENTIVE TUBERCULOSIS VACCINATION OF HEALTH CARE SERVICES}

\begin{tabular}{lll}
\hline Statements & Mean & SDV \\
\hline $\begin{array}{l}\text { The health care services offers } \\
\text { vaccine to those who are perceived } \\
\text { to be affected }\end{array}$ & & 1.476 \\
\end{tabular}

The vaccines are provided annually to curb the spread of the disease

The TB free individual has a high probability not to be affected

The administering of vaccine has significantly leads decrease of TB patients

\section{Composite mean and Std. Dev. $3.48 \quad 0.804$}

The study results show that majority of the respondents strongly agreed $[\mathrm{M}=3.02, \mathrm{SDV}=1.476]$ that the health care services offers vaccine to those who are perceived to be affected. They also agreed $[\mathrm{M}=3.86, \mathrm{SDV}=1.118]$ thatthe vaccines are provided annually to curb the spread of the disease. The majority of the respondents disagreed $[\mathrm{M}=2.82$, $\mathrm{SDV}=1.356]$ that $\mathrm{TB}$ free individual has a high probability not to be affected with a little majority holds contrary opinion. Respondents agreed [M=4.23, SDV=0.737] that the administering of vaccine has significantly leads decrease of TB patients. The results imply that vaccination of tuberculosisinfluence provision of curative and preventive tuberculosis health care services.

\section{A. M\&E Work Plan and Provision of Curative and Preventive Tuberculosis Health Care Services}

The study assessed how M\&E work plan influence provision of curative and preventive tuberculosis healthcare practices in institutions of public health. The results are presented in Table 8.

TABLE XIII: B. M\&E WORK PLAN PROVISION OF CURATIVE AND PREVENTIVE TUBERCULOSIS VACCINATION OF HEALTH CARE SERVICES

\begin{tabular}{lcc}
\hline Statements & Mean & SDV \\
\hline Finances availability for & 3.94 & 0.426
\end{tabular}

facilitation and implementation affect the curative and preventive tuberculosis health care activities

Tuberculosis curative and $4.04 \quad 0.562$ preventive health care activities are completed within the stipulated time frame to help achieve institutional set objectives 
Tuberculosis health care

3.96

0.625

programs are geared towards

the institutional plan

Health care activities progress

is reviewed accordance

to the plan

Work is scheduled based on the

health care activities

to be undertaken

\begin{tabular}{lll}
\hline Composite mean and Std. Dev. & 3.90 & 0.447
\end{tabular}

The study results indicated that majority of the respondents agreed $[\mathrm{M}=3.94, \mathrm{SDV}=0.426]$ that finances availability for facilitation and implementation. The majority of the respondents agreed $[\mathrm{M}=4.04, \mathrm{SDV}=0.562]$ that tuberculosis curative and preventive health care activities are completed within the stipulated time frame to help achieve institutional set objectives. Most of the respondents agreed $[\mathrm{M}=3.96, \mathrm{SDV}=0.625]$ that tuberculosis health care programs are geared towards to the plan. Respondents agreed $[\mathrm{M}=3.92, \mathrm{SDV}=0.718]$. The results generally show that $\mathrm{M} \& \mathrm{E}$ work plan significantly influence provision of curative and preventive tuberculosis care services in public health institutions.

TABLE XIV: REGRESSION OF M\&E WORK PLAN AND PROVISION OF CURATIVE AND PREVENTIVE TUBERCULOSISHEALTH CARE SERVICES

\begin{tabular}{|c|c|c|c|c|c|}
\hline \multirow{2}{*}{$\begin{array}{c}\text { Mode } \\
1\end{array}$} & \multicolumn{2}{|c|}{$\begin{array}{l}\text { Unstandardized } \\
\text { Coefficients }\end{array}$} & $\begin{array}{l}\text { Standardi } \\
\text { zed } \\
\text { Coefficie } \\
\text { nts }\end{array}$ & \multirow[t]{2}{*}{$\mathrm{t}$} & \multirow[t]{2}{*}{$\mathrm{Si}$} \\
\hline & B & $\begin{array}{l}\text { Std. } \\
\text { Error }\end{array}$ & Beta & & \\
\hline $\begin{array}{l}\text { [Cons } \\
\operatorname{tant}]\end{array}$ & 29.724 & 1.301 & & $\begin{array}{l}22 . \\
842\end{array}$ & $\begin{array}{c}.0 \\
00\end{array}$ \\
\hline $\begin{array}{l}\text { M\&E } \\
\text { Work } \\
\text { plan }\end{array}$ & .153 & .660 & .167 & $\begin{array}{c}2.3 \\
05\end{array}$ & $\begin{array}{l}.0 \\
02\end{array}$ \\
\hline
\end{tabular}

Predictors: [Constant], M\&E work plan

Dependent Variable: Provision of curative and preventive TB health care services

$\mathrm{R}=0.167 ; \mathrm{R}$. Square $=0.028 ; \mathrm{F}[5.513]=$ at a level of significant $\mathrm{P}=0.00<0.05$

$$
\mathrm{Y}_{3}=29.7244+0.153 \mathrm{X}_{3}
$$

The results show that there is moderately weak positive correlation between $\mathrm{M} \& \mathrm{E}$ work plan on provision of curative and preventive tuberculosis health care services with a statistically significant. The F ratio significant was F [5.513] at $\mathrm{P}=0.00<0.05$ meaning that there was statistically significant influence of monitoring and evaluation work plan on provision of curative and preventive tuberculosis health care services.
TABLE XV: REGRESSION ANALYSIS OF M\&E WORK PLAN AND PROVISION OF CURATIVE AND PREVENTIVE TUBERCULOSIS HEALTH CARE SERVICES

\begin{tabular}{lccccc}
\hline Model & $\begin{array}{c}\text { Sum of } \\
\text { Squares }\end{array}$ & df & $\begin{array}{c}\text { Mean } \\
\text { Square }\end{array}$ & F & Sig. \\
& & & & & \\
Regression & 21.774 & 1 & 21.744 & 5.313 & 0.002 \\
Residual & 757.078 & 186 & 4.092 & & \\
Total & 778.852 & 187 & & & \\
\hline
\end{tabular}

a. Predicator: [Constant], M\&E work plan

b. Dependent Variable: Provision for curative and preventive tuberculosis health care services

\section{A. Test of Hypothesis}

$\mathrm{H}_{0}$ : Monitoring and evaluation work plan significantly influence the provision of curative and preventive tuberculosis health care services in public health institutions in Kisumu County

The indicators included finances for facilitation and implementation, time frame to achieve the work, program sequences and plan review. The composite mean of these indicators was computed and used in the analysis. The test used linear regression model;

$$
\begin{aligned}
& \mathrm{y}_{3}=\mathrm{a}_{3}+\beta_{3}+\mathrm{X}_{3}+\mathrm{e}_{3} \quad \text { Where; } \\
& \mathrm{y}_{3}=\text { Provision of curative and preventive health care } \\
& \text { services } \\
& \qquad \begin{array}{l}
\mathrm{a}_{3}=\text { Constant } \\
\beta_{3}=\text { Beta coefficient } \\
\mathrm{X}_{3}=\text { M\&E work plan } \\
\mathrm{e}_{3}=\text { error term }
\end{array}
\end{aligned}
$$

The results indicated that the $\mathrm{P}$ value was $\mathrm{P}=0.000<0.05$ at a level of significance $\mathrm{P}=0.00<0.05$ that result in accepting alternative hypothesis and rejecting null hypothesis.

\section{v. CONCLUSION AND RECOMMENDATION}

M\&E work plan is essential in health care programs since it elaborate on what the program is intending to achieve, how it is going to implement it and within the specified time. It is therefore important to note that the public health institutions M\&E work plan should be inclusive that involve communication, identifying the indicators that are directly related to the health care activities to be carried out to enable the organization to achieve its objectives. The study result found that $\mathrm{M} \& \mathrm{E}$ work plan and provision of curative and preventive tuberculosis health care services had a stronger correlation efficient that contribute to the achievement of the set objectives. The M\&E Plan helps assess progress of the program toward achieving its goals and objectives. Periodic reports on this progress are used to inform key stakeholders as well as program implementers and directors. Thus, the M\&E work plan is an important tool used by M\&E officers for comprehensive planning on how to study and report on the program and its effects. 


\section{REFERENCES}

[1] Aggrarwal, A. K. \& Zairi, M. [1997]. The Role of Total Quality Management in Enabling. A Primary Health-Care Orientation. Quality Management, Vol.80

[2] Alexander, E. R. [1992]. The Public Interest in Planning: From Legitimation Substantive Plan Evaluation. DO1:10.10.11777/1473095202200100303.

[3] Campbell, H., \& Marshall, R. [2002]. Values and Professional Identities in Planning Practice. Planning Futures New Directions for Planning Theory [pp. 93-109]. London Routledge.

[4] European Commission. [2008]. Joint Report on Social Protection and Social Inclusion. Brussels.

[5] David, D. [1999]. Impact of Formal Continuing Medical Education: MD, University of Toronto, 150 College St, Toronto, Ontario, Canada.

[6] FDA. [2018]. Department of Health and Human Services. US

[7] Houghton Mifflin, (2004), Medical Dictionary. Houghton Mifflin Company. The American Heritage.

[8] Reynolds, H. W \& Elizabeth G Sutherland. [2015]. A systematic Approach to the Planning, Implementation, Monitoring, and Evaluation of Integrated Health Services. BMC Health Services Research 13:168

[9] Starfield, B., L. Shi \& Mancinko. [2005]. Contribution of Primary Care to Health Systems and Health. Milbank Quarterly 83

[10] Tilbury, D. [2007]. Monitoring and Evaluation during the UN Decade of Education for variety?" International Journal of Health Care Quality Assurance, Vol. 23 No. 4.

[11] UNAIDS. [2010]. Joint United Nations Programme on HIV and AIDS [UNAIDS]: Basic Terminology and Frameworks for Monitoring and Evaluation. Geneva

[12] United Nations. [2000]. United millennium declaration, Resolution UN HQ New York.

[13] World Health Organization. [2019]. Everybody's Business: Strengthening Health Systems to Improve Health OutcomesWHO's Framework For Action. Geneva.

[14] World Health Organization. [2011]. Global Tuberculosis Report.Geneva.

[15] World Health Organization. [2008]. Global Tuberculosis Control: Surveillance, Planning, Financing. Geneva.

\section{AUTHORS'S PROFILE}

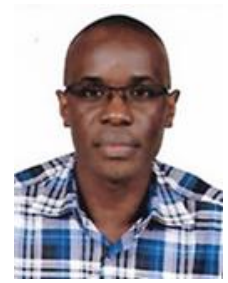

John Odhiambo Oluoch is from Siaya County, Kenya 25th May, 1975. PhD in Project Planning and Management (Monitoring and Evaluation), Master's degree in Project Planning and Management and Bachelor's degree in political science and public administration and a diploma in human resource management all from the University of Nairobi. He is a researcher and involved in implementation and monitoring of upgrading projects in informal settlement in Kenya with a NGO's and faith-based organization for the last seven years. Currently, he is a lecturer at the ODEL Campus, University of Nairobi.

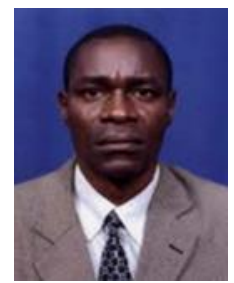

Professor Charles M. Rambo is a professor in the School of Continuing and Distance Education at the University of Nairobi. He holds a PhD Degree in Financing Distance Education from the University of Nairobi Kenya, MBA Degree in Finance of Newport University, California, USA with Courses in Finance [major], research and other management courses and a BBA Degree with a major in finance and a minor in accounting of Newport University- California USA. Degree status 3.72 GPA. He contributes immensely to the body of knowledge research, continuous teaching, examining and research. He has thorough supervision of postgraduate students. He also teaches postgraduate students at the School of Business, University of Nairobi. $\mathrm{He}$ has several publications on various researched articles including international referred journals and published text books namely, Social Science Research: Principles, Methods, Principles of Market, Fund Raising for Project Development, Financial Management for Small Business Enterprises: Theory and Practice, Financing in Distancing Learning in Kenya: A Focus on Bachelor of Education Arts Program of The University of Nairobi, Fundamentals of Financial Management: A Strategic Approach, Disaster's , Their Impacts, Insurance, Risk Financing and Management, Principles and Procedures In Project Planning and Management, Project Financing, Material Production and Control Strategies, Developing and Implementing Strategic Marketing Plans and Small Enterprises Development and Management. He developed modules Entrepreneurship and Small Business Management and Fundamentals of Management by distance learning of the University of Nairobi. He also participated in development for the University of Nairobi postgraduate programs namely; Doctor of Philosophy $[\mathrm{PhD}]$ in Project Planning and Management, master's Programmes in Project Monitoring and Evaluation, Master of Project Financing, Master Degree in Project Planning and Management and a Bachelor Degree in Project Planning and Management. Master's Degree in Project Planning and Management He is an External Examiner at the University of Eastern Africa, Baraton and Jaramogi Odinga University of Science and Technology, University of Daressa-laam from 2010 to date. He has presented the listed paper in conferences; the linkage between Business Strategy And Human Resource Strategy On The Performance Of An Organization, At A Regional Conference of the Institute of Human Resource Management Professionals in Kisumu county, Kenya, Aspects of Revenue Generation that Influence Financial Sustainability of Public- Private Water Utilities: The Case of Lake Victoria South Region, Kenya, The Role of The Institute of Human Resource Management Professionalism Achieving Kenyan Vision 2030 In A Regional Conference held In Kisumu County, Kenya Just to mention but a Few. His Membership with Professional Association are; Kenya Institute of Management [KIM], Number: 44234 and Certified financial analyst [CFA], [UK] Membership ID: 68359054. He holds the following Special Assignments and Appointments; Chairman, Departmental Postgraduate Committee -Department of Open Learning, University of Nairobi, Chief Editor of the International Journal of Project Management, University of Nairobi. Ad-Hoc Reviewer by institute for business and finance researchUSA.

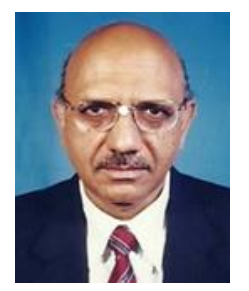

Prof. Ganesh Pokhariyal is a professor in applied mathematics in School of Mathematics at the University of Nairobi. He has actively taught, research and supervise in higher learning institutions for over thirty years. He has contributed immensely in research with interests in, General theory of relativity Differential Geometry and Mathematical Modelling. He has over 120 publications in various fields including Medicine, Governance and Agriculture. Also held various administrative offices in the University of Nairobi.D.Sc. [Mathematics] - General Relativity and Differential Geometry. Mathematics, Ph.D. [Mathematics] - General Theory of Relativity, M.Sc. [Mathematics] - Mathematical Statistics I and II, Relatively and Quantium Mechanics, M.Sc [Physics] - Spectroscopy. His research interest General Theory of Relativity, Differential Geometry and Mathematical Modeling. He has trained many Postgraduate students in Applied Mathematics, Pure Mathematics, Information Systems, Physics and Engineering. Ph.D. Supervision in Differential Geometry, Relativity Theory, Functional Analysis, Statistical analysis and Mathematical Modeling. Ph.D. teaching and supervision at School of Commerce, Nairobi University. Trained MBA students at Moi University and United States International University [Nairobi]. He developed curriculum for B.Sc. and M.Sc. Applied Mathematics for the University of Nairobi and Statistics and Quantitative Methods for the Kenya Institute of Management. Postgraduate Information Systems, Physics and Engineering. Ph.D. Supervision in Differential Geometry, Relativity Theory, Functional Analysis, Statistical analysis and Mathematical Modeling. Ph.D. teaching and supervision at School of Commerce, Nairobi University. Trained MBA students at Moi University and United States International University [Nairobi]. He developed curriculum for B.Sc. and M.Sc. Applied Mathematics for the University of Nairobi, Statistics and Quantitative Methods for the Kenya Institute of Management, Secondary School Subject for the Kenya Institute of Education and Mathematics and statistics units for United States International University [Nairobi]. 